\title{
Elke Scherstjanoi (dir.) Russlandheimkehrer. Die sowjetische Kriegsgefangenschaft im Gedächtnis der Deutschen
}

München :Oldenbourg, 2012, 264 p

Paul Pasteur

\section{OpenEdition}

\section{Journals}

Édition électronique

URL : http://journals.openedition.org/ifha/8182

DOI : $10.4000 /$ ifha. 8182

ISSN : 2198-8943

\section{Éditeur}

IFRA - Institut franco-allemand (sciences historiques et sociales)

Référence électronique

Paul Pasteur, «Elke Scherstjanoi (dir.) Russlandheimkehrer. Die sowjetische Kriegsgefangenschaft im Gedächtnis der Deutschen », Revue de l'IFHA [En ligne], Date de recension, mis en ligne le 14 avril 2015, consulté le 22 septembre 2020. URL : http://journals.openedition.org/ifha/8182 ; DOI : https://doi.org/ 10.4000/ifha.8182

Ce document a été généré automatiquement le 22 septembre 2020

(C)IFHA 


\title{
Elke Scherstjanoi (dir.) Russlandheimkehrer. Die sowjetische Kriegsgefangenschaft im Gedächtnis der Deutschen
}

München :Oldenbourg, 2012, 264 p

\author{
Paul Pasteur
}

L'éditrice Elke Scherstjanoi poursuit l'ambitieux projet de renouveler l'historiographie concernant les prisonniers allemands en Union soviétique. Depuis quelques années, les études se sont développées sur le sujet, et l'éditrice désire s'arrêter sur les représentations de ces prisonniers dans les deux États allemands après 1945. Néanmoins, pour un lecteur non-averti, l'ouvrage pose problème dès le départ: dans son introduction, l'éditrice analyse des images et leur réception avant et après 1990, mais elle oublie tout simplement de rappeler les éléments contextuels indispensables, dont le nombre de prisonniers concernés, qui n'apparaît que bien plus tard dans un article, ainsi qu'un minimum de références historiographiques.

Cet ouvrage, issu d'un colloque tenu en 2008, rassemble treize contributions d'historiens, de slavistes, germanistes, spécialistes de littérature ou du cinéma. Au centre de l'ouvrage, on retrouve le souci d'examiner les représentations des prisonniers allemands en Union soviétique en RFA et en RDA (bien qu'il n'y ait que deux articles explicitement consacrés à cette dernière) à travers la littérature, la diversité des histoires et les films réalisés dans les deux États allemands ainsi qu'après la réunification. Dans un de ses deux articles, l'éditrice désire revenir sur la comparaison entre les deux républiques, mais ses sources sont dès le départ biaisées dans la mesure où, sur 85 interviews d'anciens prisonniers de guerre, 68 sont celles d'anciens Allemands de l'Est. L'ouvrage veut souligner la césure que représente 1989/90 dans les représentations de ces prisonniers allemands. La représentation anticommuniste, antisoviétique de l'ancienne République fédérale céderait la place à une image qui est celle d'une "grande école de la vie », du moins c'est ce qu'il ressort des témoignages 
des interviewés dans la seconde moitié des années 2000. Les articles de Berthold Peztinna sur les rapports ouest-allemands sur la captivité en Union soviétique et de Helmut Peitsch sur le film ouest-allemand Wunschkost nuancent néanmoins cette affirmation.

Un article très intéressant revient sur la captivité lors de la Première Guerre mondiale en Russie et examine les permanences dans les représentations des prisonniers en Russie et en Union soviétique. On oublie souvent que certains hommes ont vécu les deux guerres et qu'ils ont entendu les récits de leur père ou de proches qui avaient été prisonniers en Russie.

On retiendra aussi la troisième contribution d'Elke Scherstjanoi qui s'intéresse aux représentations des femmes soviétiques médecins dans les camps de prisonniers, représentations qui tranchent avec les clichés véhiculés lors de la guerre froide en RFA. Elena Müller propose, elle, une contribution qui prend l'image à l'envers, puisqu'il s'agit des représentations des prisonniers allemands dans les films soviétiques.

Cet ouvrage, comme le veut ce type de publication, manque d'homogénéité et part un peu dans tous les sens, mais a le mérite de s'interroger sur les représentations de ces prisonniers allemands en Union soviétique, qui ont été au centre des préoccupations des proches mais aussi des responsables politiques pendant plusieurs années. L'ouvrage propose de nombreuses illustrations qui concernent la vie quotidienne des prisonniers mais qui ne mettent en scène que des individus, la masse des prisonniers n'étant pas suffisamment pris en compte dans ces documents.

\section{INDEX}

Index chronologique : Époque contemporaine

Thèmes : Histoire militaire, Histoire des femmes et du genre

\section{AUTEUR}

\section{PAUL PASTEUR}

Université de Rouen 